\title{
AÇÕES LÚDICO-EDUCATIVAS PARA O ENFRENTAMENTO DA DOENÇA DENGUE EM CINCO ESCOLAS PÚBLICAS DA GRANDE BELO HORIZONTE: UMA ANÁLISE A PARTIR DA CATEGORIA SEXO
}

\author{
ACCIONES LÚDICO-EDUCATIVAS PARA EL ENFRENTAMIENTO DE LA \\ ENFERMEDAD DENGUE EN CINCO ESCUELAS PÚBLICAS DE LA GRAN BELO \\ HORIZONTE: UN ANÁLISIS DESDE LA CATEGORÍA SEXO
}

\author{
PLAYFULNESS EDUCATIVE ACTIONS TO FIGHTING THE DENGUE FEVER \\ DISEASE IN FIVE PUBLIC SCHOOLS OF BELO HORIZONTE METROPOLITAN \\ AREA: AN ANALISYS FROM THE SEX CATEGORY
}

Marcel de Almeida FREITAS ${ }^{1}$

Tiago Gonçalves de AZEVEDO ${ }^{2}$ Adla Betsaida Martins TEIXEIRA ${ }^{3}$

RESUMO: O artigo discute resultados de uma pesquisa realizada entre 2010 e 2015 sobre conhecimentos acerca da doença dengue entre discentes de três escolas públicas em Sete Lagoas e duas em Belo Horizonte através da análise comparativa por sexo. Os sujeitos do estudo foram alunos dos ensinos Fundamental e Médio e os dados foram coletados por intermédio de um mesmo questionário aplicado antes e depois de um procedimento lúdico, o Jogo da Dengue. A iniciativa foi desenvolvida pela Equipe Educação do Instituto Nacional de Ciência e Tecnologia em Dengue, INCT-UFMG. Foram investigados os conhecimentos dos estudantes sobre a doença a partir de quatro eixos temáticos: 1- ações domésticas e ações comunitárias; 2- ações político-sociais e ações governamentais; 3- aspectos biomédicos; 4aspectos geográficos e climáticos. Em geral os índices de conhecimentos femininos foram superiores aos masculinos em três dos quatro eixos, especialmente no ensino fundamental. No Ensino Médio os percentuais de acertos dos meninos subiram, porém, ainda ficaram inferiores aos femininos, exceto no quesito aspectos geográficos e climáticos.

PALAVRA-CHAVE: Dengue. Saúde coletiva. Relações de gênero. Ludicidade e educação.

RESUMEN: El artículo discute resultados de un estudio hecho entre 2010 y 2015 sobre conocimientos acerca de la enfermedad dengue entre alumnos de tres escuelas públicas en Sete Lagoas y dos escuelas en Belo Horizonte a través de análisis comparativo por sexo. Los actores de la investigación fueron alumnos de los niveles primario y secundario y los datos fueron recolectados por medio de una misma encuesta aplicada antes y después de una

${ }^{1}$ Centro Federal Tecnológico de Minas Gerais (CEFET-MG), Belo Horizonte - MG - Brasil. Doutor em Educação. Sociólogo, Professor DCSF/CEFET-MG. ORCID: http://orcid.org/0000-0003-4928-2136. E-mail: marcel.fae.ufmg@gmail.com

${ }^{2}$ Universidade Federal de Minas Gerais (UFMG), Belo Horizonte - MG - Brasil. Especialista em Docência do Ensino Superior, bolsista do Programa ICNT-Dengue. ORCID: http://orcid.org/0000-0002-5680-429X. E-mail: tiago.gaze@gmail.com

${ }^{3}$ Universidade Federal de Minas Gerais (UFMG), Belo Horizonte - MG - Brasil. Professora Associada FaE/UFMG. Doutora em Educação, University of London. ORCID: http://orcid.org/0000-0001-5400-470X. Email: adlaufmg@gmail.com

RIAEE - Revista Ibero-Americana de Estudos em Educação, Araraquara, v. 14, n. 4, p. 2222-2243, out./dez., 2019. E-ISSN: 1982-5587. 
actividad lúdica, el Jogo da Dengue (El Juego de la Dengue). La iniciativa fue desarrollada por el Equipo Educación del Instituto Nacional de Ciência e Tecnologia em Dengue, INCTUFMG. Fueron pesquisados los conocimientos de estudiantes sobre la enfermedad en cuatro ejes temáticos: 1-acciones domésticas y acciones comunitarias; 2- acciones político-sociales y acciones gubernamentales; 3- aspectos biomédicos; 4- aspectos geográficos y climáticos. De modo general los índices de conocimientos femeninos fueron superiores a los masculinos en tres de los cuatro ejes, sobretodo en el nivel primario de enseñanza. En la enseñanza secundario los porcentuales de aciertos de los niños subieron, pero, aún quedaron más bajos que los femeninos, excepto en el quesito aspectos geográficos y climáticos.

PALABRAS CLAVE: Dengue. Salud colectiva. Relaciones de género. Ludicidad y educación.

ABSTRACT: The article discusses results of a research done from 2010 to 2015 on knowledge about disease dengue fever among students in three public schools of Sete Lagoas and two schools in Belo Horizonte through a comparative analysis based on sex. The study's actors were students of elementary and secondary level and the data collected by a same survey ordered before and after a playful procedure, O Jogo da Dengue (the Dengue Game). The initiative was developed by Education Team of Instituto Nacional de Ciência e Tecnologia em Dengue, INCT-UFMG. Student's knowledges are investigated in four themes about this disease: 1-domestic and community actions; 2- political and social actions and governmental actions; 3- biomedical aspects; 4- geographic and climatic aspects. In general female indicators were higher than males in three of four aspects evaluated, especially on elementary education. On secondary level the masculine percentages rise, however, still were under to the feminine ratios, except on geographic and climatic themes.

KEYWORDS: Dengue fever. Collective health. Gender. Playfulness and education.

\section{Introdução}

Refletir sobre a questão de gênero na escola é pensar sobre as diferenças socioculturais de aprendizagem que configuram a realidade da sala de aula. Logo, se faz necessário que as educadoras e os educadores conheçam as dinâmicas comportamentais que muitas vezes já vem pré-estabelecidas entre meninos e meninas pela sociedade externa à escola, processos estes que fazem com que os educandos possam ter acesso diferenciado aos conteúdos escolares, ou mesmo o não acesso a alguns deles, em função de questões como estereótipos de gênero ou afinidades socialmente construídas por determinados assuntos em função do sexo.

Criado em 2002, o Programa Nacional de Controle da Dengue (PNCD) possui entre seus componentes um objetivo explícito no que tange à educação em saúde, ao defender que é preciso “[...] fomentar o desenvolvimento de ações educativas para a mudança de comportamento e a adoção de práticas para a manutenção do ambiente domiciliar preservado da infestação por Aedes aegypti, observadas a sazonalidade da doença e as realidades locais 
quanto aos principais criadouros" (BRASIL, 2002, p. 9). Com isso, segundo Shall (2015), a educação em saúde deve vir associada à comunicação social e à mobilização coletiva, com o escopo de envolver as pessoas no controle da doença por meio de práticas integradas que incluem a participação de instituições de ensino, pesquisa, saúde e demais setores.

Contudo, a partir da análise desta autora, é possível observar que ainda é dada pouca atenção a ações contínuas de educação com potencial de impacto na prevenção do agravo de certas enfermidades e na melhoria da qualidade de vida. Para Shall $(2015$, p. 359), "[...] tais ações deveriam ser incluídas de forma permanente e interativa nos espaços formais e não formais de ensino, nos serviços de saúde e nas comunidades". É preciso pensar a educação permanente, sendo abrangente no que tange às perspectivas da intersetorialidade de forma urgente, "[...] incluindo novas tecnologias e abordagens dialógicas e participativas" (SHALL, 2015, p. 358).

Contribuindo neste sentido, o texto apresenta alguns resultados da pesquisa Ações Educativas no Controle e Combate à Doença Dengue, iniciativa desenvolvida em escolas da região metropolitana de Belo Horizonte, MG, pela equipe Educação do INCT Dengue/UFMG e financiada pelo CNPq, CAPES e FAPEMIG ${ }^{4}$. O projeto foi vencedor da $1^{\text {a }}$ edição do Prêmio ODM Minas - Objetivos do Milênio em 2014, além de ter sido finalista em premiação similar pela Casa Civil da Presidência da República, ambos os prêmios na categoria 6: Combater a AIDS, a Malária e Outras Doenças ${ }^{5}$. As iniciativas que possibilitaram a efetivação desta investigação interventiva foram as parcerias entre as Faculdades de Educação, de Enfermagem e Medicina da UFMG.

Para o levantamento dos dados analisados, o critério de escolha das escolas foi baseado nas realidades de suas comunidades, bem como em fatores sociais e indicadores referentes à dengue. Baseado em dados do Ministério da Saúde em 2010, a cidade de Sete Lagoas então apresentava elevados índices de casos de Dengue e priorizava políticas públicas de controle e combate à doença.

O mesmo questionário foi aplicado pré e pós Jogo da Dengue, com 6 perguntas abertas e 36 fechadas relacionadas à doença em três escolas municipais de Sete Lagoas com alunos do $7^{\circ}$ ano do Ensino Fundamental em 2010. Portanto, os sujeitos do estudo naquele locus estavam na faixa dos 12 a 14 anos. Além dessas instituições, tais ações se deram em outras duas escolas de Belo Horizonte: Escola Estadual Dom Pedro II, com o sétimo ano do

${ }^{4}$ INCT Dengue. Instituto Nacional de Ciência e Tecnologia, ICB - Instituto de Ciências Biológicas da UFMG. CNPq e Fapemig. Disponível em: http://www.inctdengue.icb.gov.br/home. Acesso em 23/01/2015.

${ }^{5}$ ODM MINAS/BRASIL - Objetivos do Milênio, PNUD. Casa Civil da Presidência da República. Disponível em: http://www.pnud.org.br/odm.aspx. Acesso em: 23/01/2015. 
Ações Lúdico-Educativas para o enfrentamento da doença dengue em cinco escolas públicas da Grande Belo Horizonte: uma análise a partir da categoria sexo

Ensino Fundamental (em maio/2012) e o primeiro ano do Ensino Médio (08/2012), além do Instituto de Educação de Minas Gerais, com o $9^{\circ}$ ano do Ensino Fundamental (04/2014) e o $2^{\circ}$ ano do Ensino Médio (08/2014).

As conexões entre as duas aplicações do questionário e o Jogo da Dengue entre elas, prática lúdica inserida entre os dois questionários idênticos, foram importantes ferramentas para o sucesso do projeto, promovendo a coleta de dados sobre os conhecimentos anteriores dos alunos sobre o tema, para o desenvolvimento e o aprimoramento deste recurso lúdico em sala de aula; os resultados obtidos pelas intervenções educativas serviram de ferramenta para o refinamento do projeto. A metodologia mostrou-se bastante concisa e de fácil aplicação para a coleta e análise de dados, adaptando-se relativamente bem ao tempo convencional de uma aula, isto é, 50 minutos.

Por questões práticas, ou seja, para que o tempo não ultrapassasse uma aula de 50 minutos e para que a ação lúdica fosse mais dinâmica, e também por questões didáticas segundo Veiga Neto (1996), a punição em geral cria bloqueio e até traumas no processo de aprendizado -, suprimiu-se o tradicional recuo de casas no caso de erro, ou seja, ao tirar uma ficha com uma pergunta sobre a dengue, caso o discente errasse ele não voltava o número de casas que havia saído no dado, como tradicionalmente acontece nesses tipos de brincadeiras, mas ficava apenas estacionado até chegar novamente sua vez de tirar uma carta e jogar o dado. Abaixo imagem ilustrativa do tabuleiro do Jogo da Dengue, em torno do qual se reuniam de 4 a 5 alunos em cada grupo.

Figura 1 - modelo de tabuleiro usado no Jogo da Dengue (imagem ilustrativa).

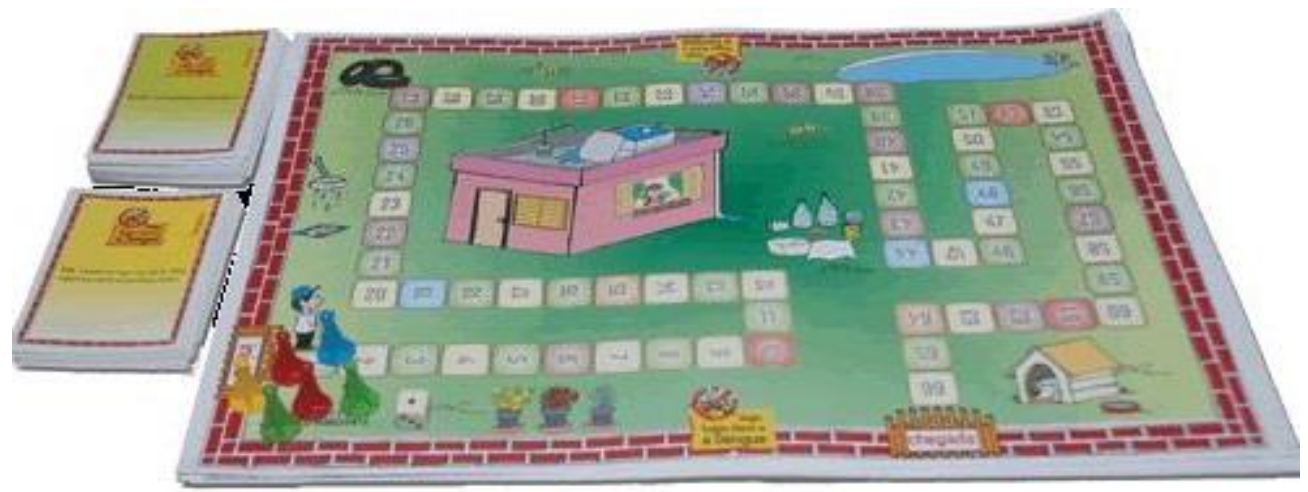

Fonte:

http://www.ufmg.br/online/arquivos/020434.shtmlhttps://www.ufmg.br/online/arquivos/020434.shtml 
O Jogo da Dengue passou por alterações sugeridas pelos próprios alunos, como modificações no tabuleiro e a inserção de figuras resultantes de iniciativas da equipe Educação durante as coletas de dados e aplicações do jogo. A parceria com o PIBIDPedagogia $^{6}$ da Faculdade de Educação da UFMG possibilitou ampliar a atuação e a abordagem de um tema extremamente importante, a saúde coletiva a partir da doença dengue, ou seja, foi a partir da inserção dos bolsistas do PIBIB nas escolas que a equipe da UFMG conseguiu levar tal estratégia lúdico-educativa para as instituições de ensino em questão.

Com os dados obtidos e devidamente contrastados para análise, foi possível melhor conhecimento das realidades presentes nas famílias, comunidades e, especialmente, a concepção vinculada à saúde coletiva dos alunos. Tais articulações mostraram-se decisivas para a sugestão de medidas e de ações mais orientadas em cada região avaliada, permitindo o desenvolvimento de materiais e de metodologias harmonizadas às realidades e peculiaridades culturais e socioeconômicas locais que, segundo Mariano (2008), às vezes dificultam avanços sociais através da educação, como é o caso da saúde coletiva, porque se distanciam dos saberes locais prévios.

De modo geral esta intervenção lúdica, a aplicação do mesmo questionário antes e depois de que os alunos participassem do Jogo da Dengue, confirmou estatísticas nacionais referentes ao desempenho dos alunos em termos de sexo: o desempenho das meninas foi um pouco superior ao dos meninos, especialmente no Ensino Fundamental e, tanto nas escolas da região central de Belo Horizonte quanto nas três escolas de uma região pobre da periferia da capital, houve atuação da variável sexo.

\section{Breve nota sobre questões de gênero e aprendizagem}

O trabalho aqui apresentado parte do pressuposto de que as alunas e os alunos reais dentro da sala de aula são compostos por diversos tipos de sujeitos e que um dos atravessamentos mais importantes neste fenômeno, ao lado de classe social, das diferenças geracionais ou de raça/etnia, por exemplo, dizem respeito às diferenças socialmente construídas entre mulheres e homens (RIBEIRO; QUADRADO, 2013).

Alguns estudos também salientam a relativa independência (mas, ao mesmo tempo, a mútua interferência) das relações de gênero referentes às estabelecidas social e historicamente, isto é, das construídas diferenças 'vocacionais' e de aprendizagem entre

${ }^{6}$ Programa Institucional de Bolsas de Iniciação à Docência (PIBID). Programa de formação docente do governo federal, presente em instituições públicas e particulares e envolvendo professores das escolas conveniadas e professores universitários visando a melhoria da qualidade da educação. 
Ações Lúdico-Educativas para o enfrentamento da doença dengue em cinco escolas públicas da Grande Belo Horizonte: uma análise a partir da categoria sexo

meninas e meninos em relação às questões raciais e de classe social, quer dizer, tais estudos ressaltam que as diferenças, preferências por certas disciplinas e/ou dificuldades de aprendizagem em determinados conteúdos não podem ser reduzidas às questões de classe socioeconômica e/ou às étnico-raciais (ABRAMOVAY; CASTRO, 2006).

As estatísticas nacionais sobre desempenho escolar nos ensinos fundamental e médio, embora muitas vezes pontuais ou, ao contrário, muito generalistas no que se refere à categoria sexo, demonstram que existem diferenças entre meninas e meninos ao longo da infância e adolescência, indicando, grosso modo, que os meninos teriam um pouco mais de dificuldade em alguns conteúdos enquanto que as meninas se destacariam um pouco mais em outros e na disciplina em geral da sala de aula (RIBEIRO; QUADRADO, 2013).

Assim, vários trabalhos afirmam que, geralmente, as meninas são socializadas para serem mais tranquilas e adaptadas ao que se espera de um aluno tradicional dentro de sala, enquanto que os meninos são mais agitados, não obstante este quadro venha se alterando em função das próprias dinâmicas internas da escola e, sobretudo, em razão das transformações da sociedade mais ampla (FERNÁNDEZ, 2010). No que diz respeito ao aprendizado especificamente, algumas pesquisas mostram leve prevalência feminina no desempenho geral e que elas se destacam em alguns conteúdos como História, Artes e Língua Portuguesa, enquanto que eles se sobressaem em Matemática, Química e Física.

Ao longo da coleta de dados observou-se, de maneira geral em todas as escolas, principalmente nas três localizadas na periferia de Belo Horizonte, que o coletivo de meninos apresentava comportamento mais agitado e falante que o coletivo de meninas e que o grupo das meninas tinha uma postura mais comedida, seguramente, mais apreciada e incentivada pelo sistema escolar típico, considerado mais apropriado à execução das atividades e à aprendizagem em geral. Isso não quer dizer que todos os meninos eram agitados e que todas as meninas eram tranquilas: esta ilação se refere aos alunos separados por grupo de sexo.

A Escola Estadual Pedro II, na área central da capital mineira, não em função de questões de gênero, mas pelo tipo de alunado que possui, apresentou relativa nuança nessa dinâmica, ou seja, o comportamento de meninos (enquanto grupo, embora ali também houve exceções individuais) e o comportamento das meninas não foram tão díspares assim, quer dizer, notou-se que os meninos eram mais 'disciplinados' que os outros das outras escolas pesquisadas e que as meninas desta escola eram mais 'ativas' se comparadas à maioria das outras meninas das outras instituições onde também se deu a intervenção lúdico-didática.

No que refere à aplicação do mesmo questionário em dois momentos distintos intercalados pelo Jogo da Dengue, notou-se uma situação interessante ligada às relações 
sociais entre os sexos: em geral, no Ensino Fundamental, os grupos de 4 a 5 alunos tendiam a ser monossexuais, enquanto que nas turmas de Ensino Médio já havia mais presença de grupos mistos de garotas e de garotos. Inclusive duas situações ligadas a gênero nos chamou a atenção: na turma do Ensino Médio da Escola Pedro II um dos grupos era formado por 3 meninos e uma menina e outro grupo exatamente o contrário, um menino e três meninas.

De acordo com os Parâmetros Curriculares Nacionais (PCNs, 1998), as questões de gênero devem estar inseridas nos temas transversais, devendo o processo de ensinoaprendizagem enfatizar a construção social dos padrões estabelecidos de masculino e de feminino, apontando que eles são históricos, isto é, mudam ao longo do tempo e variam de uma cultura para outra. Os profissionais da escola, então, devem ter em mente que tais valores e condutas de gênero são transmitidos pela Educação (assim como por outros veículos socioculturais), transformando-se em representações imagens, aptidões e comportamentos internalizados, ou seja, o desempenho e a predileção por certas matérias em meninos e em meninas não têm nada de biológico ou de genético (VEIGA NETO, 1996).

Isso ficou claro em nossa prática de intervenção via questionário e Jogo da Dengue, pois, ao se analisar a distribuição do alunado no espaço da sala de aula, em geral, tanto nas escolas de Belo Horizonte quanto nas da cidade de Sete Lagoas, no Ensino Fundamental as meninas tendiam a sentar mais à frente e nas laterais, nas fileiras próximas à porta e da janela, bem como formar grupos mais heterogêneos de sexo, enquanto que os meninos se sentavam mais no centro da sala e no fundo da sala, ocorrendo também mais grupos monossexuais entre eles no Ensino Fundamental que no Médio.

Tendo essas especificidades já sido constatadas em estudos anteriores em outros contextos, inclusive que se mantêm relativamente com certa coerência em escolas de comunidades carentes e em escolas particulares ditas de 'elite' (FERNÁNDEZ, 2010), os Parâmetros Curriculares Nacionais (1998) recomendam que, em termos das relações de gênero, os/as educadores/as deveriam buscar transmitir aos alunos e às alunas a valorização da equidade entre os sexos e o respeito a cada sujeito individualmente, em sua singularidade, independentemente se se trata de uma pessoa do sexo feminino ou masculino ou qual é sua orientação sexual.

Neste sentido, o professorado, bem como outros membros da equipe escolar, não deve 'fazer vista grossa' para possíveis preconceitos sociais e, do ponto de vista de alguma discriminação individual e/ou algum problema ou defasagem individual ligada às diferenças entre os sexos, deve intervir no sentido de dirimir ou mesmo eliminar tais obstáculos e problemas visando uma educação mais justa, inclusiva e cidadã. 
Ações Lúdico-Educativas para o enfrentamento da doença dengue em cinco escolas públicas da Grande Belo Horizonte: uma análise a partir

\section{Apresentação dos lugares e dos sujeitos do estudo}

Buscando facilitar a compreensão do papel de cada etapa para a obtenção dos resultados e para as análises do presente estudo, em cada instituição o número de sujeitos envolvidos na coleta de dados, composta por 1- aplicação de questionário, 2- intervenção lúdica Jogo da Dengue, 3- aplicação do mesmo questionário, foi o seguinte:

Três escolas municipais da cidade de Sete Lagoas, região metropolitana de Belo Horizonte, total de 47 alunos apenas do Ensino Fundamental:

Gráfico 1 - percentual de alunos no Ensino Fundamental, Sete Lagoas - MG

\section{Ensino Fundamental}

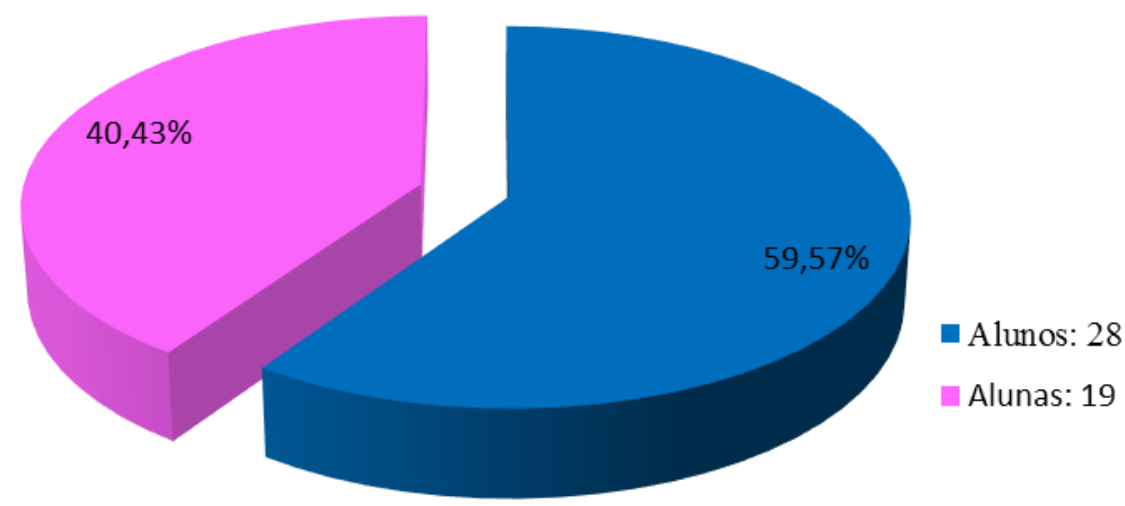

Escola Estadual Dom Pedro II, região central de Belo Horizonte, total de 60 alunos (29 do Ensino Fundamental e 31 do Ensino Médio). Observou-se que quando se passa do Ensino Fundamental ao Médio os números absolutos e percentual de alunos do sexo masculino se reduzem drasticamente: 
Gráfico 2 - percentual de alunos no Ensino Fundamental, E. E Pedro II

\section{Ensino Fundamental}

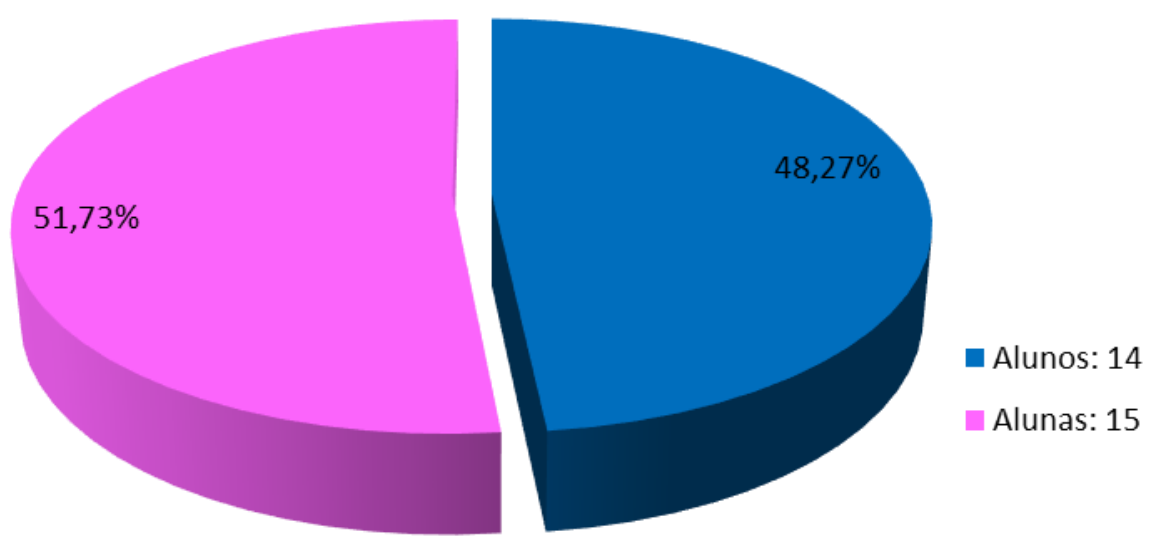

Gráfico 3 - percentual de alunos no Ensino Médio, E. E. Pedro II

\section{Ensino Médio}

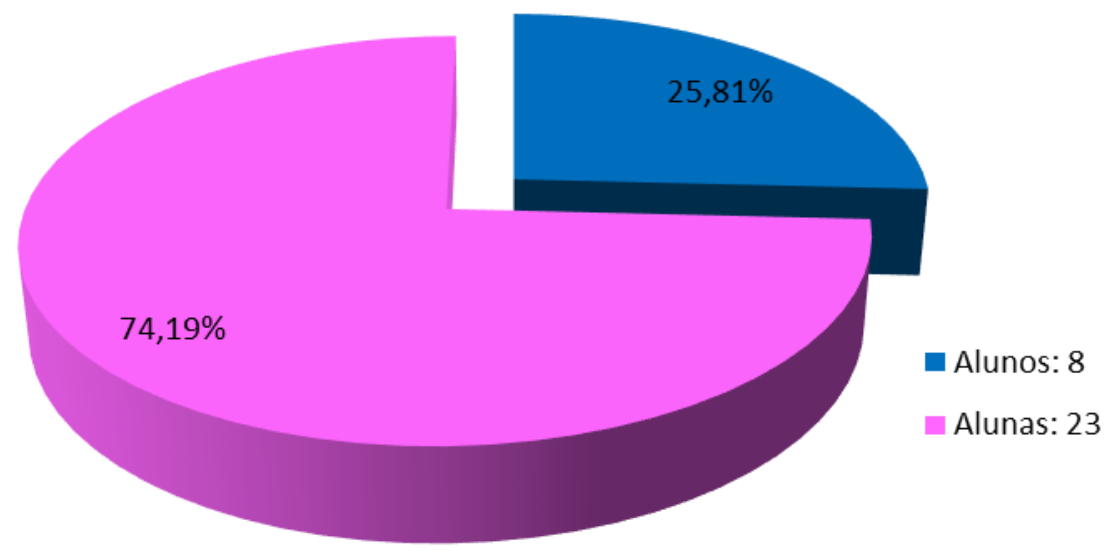

Instituto de Educação de Minas Gerais (IEMG), região central de Belo Horizonte, total de 59 discentes (29 do Ensino Fundamental e 30 do Ensino Médio). Nesta instituição o número de alunas e de alunos se manteve praticamente inalterado quando se passou do Ensino Fundamental ao Médio, sendo que as meninas foram maioria nos dois níveis de ensino: 
Gráfico 4 - percentual de alunos no Ensino Fundamental, IEMG

\section{Ensino Fundamental}

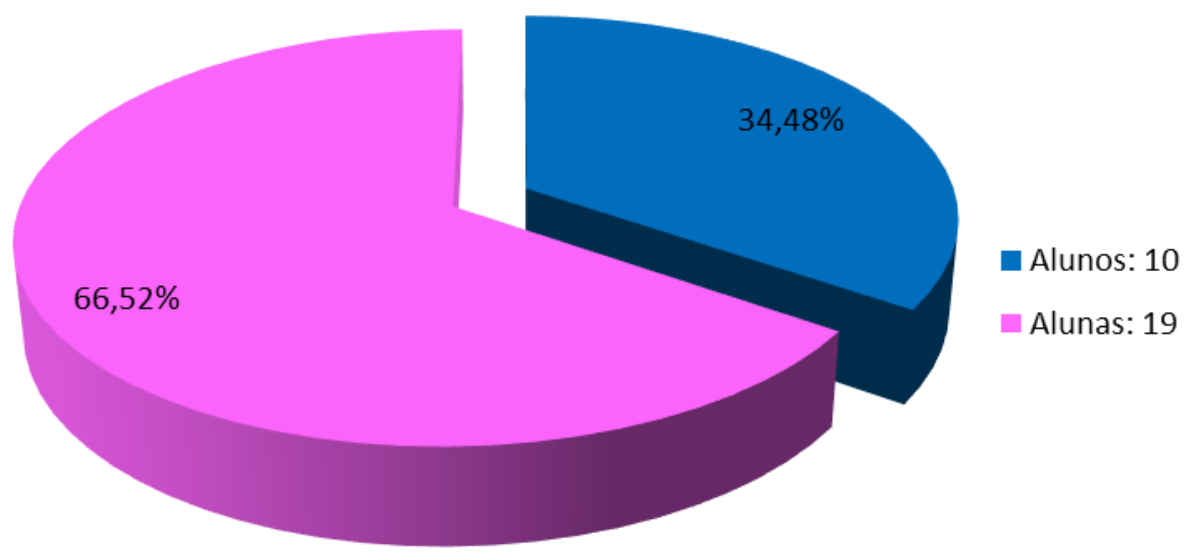

Gráfico 5 - percentual de alunos no Ensino Médio, IEMG

\section{Ensino Médio}

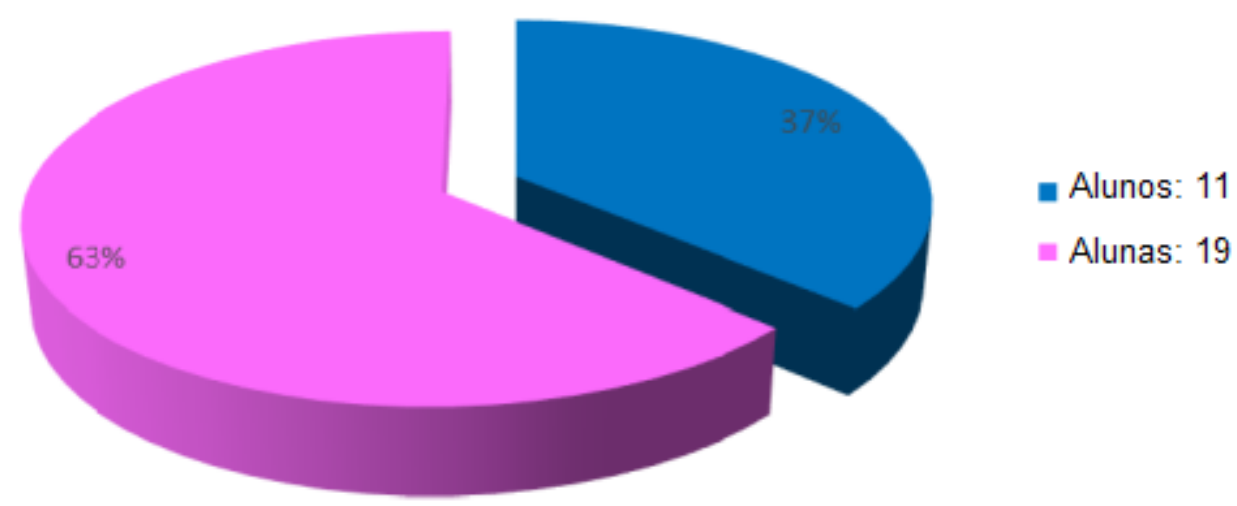

Considerando que se trata de uma pesquisa cuja variável é o sexo, é imperioso destacar que uma das escolas melhor conceituadas na avaliação da Secretaria de Educação de Minas Gerais, a Escola Estadual Dom Pedro II, tem maioria de meninas entre os pesquisados, ao passo que as três escolas públicas de Sete Lagoas, cidade da Região Metropolitana de Belo Horizonte em seu vetor noroeste, tendo sido classificadas com notas abaixo da média nacional 
e estadual nas avaliações do $\operatorname{IDEB}^{7}$ em 2012 e 2013, estão em uma área pauperizada e periférica daquela cidade, e apresentam maioria masculina entre os discentes.

O questionário, desenvolvido em 2010 após pré-testes e levantamentos provenientes de análises de temas essenciais à coleta e ao desenvolvimento de materiais didáticos sobre dengue, levou em consideração as faixas etárias mais adequadas à metodologia de pesquisa, a saber, adolescentes de ambos os sexos com idade a partir de 12 anos. Isso porque estudos como o de Silveira (2009) têm demonstrado que, em geral, conteúdos científicos são bastante distantes da realidade de diversos segmentos populacionais adolescentes, especialmente moradores de periferias, além do que a rotina típica de ensino em sala de aula vem se mostrando como pouco motivadora no processo de aprendizagem e de aquisição de conhecimento sobre esses temas, já que, frequentemente, se baseia no conteudismo do processo de transmissão por parte dos professores e no automatismo no processo de retenção por parte do alunado.

A marcação temporal do processo educativo foi a seguinte: aplicação do questionário, uma semana depois o Jogo da Dengue era aplicado na mesma turma e, por fim, na semana seguinte, era aplicado o mesmo questionário, ou seja, num intervalo de mais ou menos 15 dias a mesma turma passava por questionário-jogo-questionário a fim de se avaliar possíveis impactos deste processo lúdico-educativo nas turmas em relação à temática dengue. O questionário foi composto por seis questões abertas, que atendem ao eixo temático aspectos psicológicos (não abordadas no presente artigo) e outras 36 questões fechadas que englobam outros quatro eixos temáticos (sobre os quais versa o presente texto), e que vem a ser: ações domésticas e ações comunitárias (3 questões); ações político-sociais e ações governamentais (4 questões); aspectos biomédicos (21 questões); aspectos geográficos e climáticos (4 questões).

De forma geral houve êxito durante as aplicações em todas as escolas, porém, ainda assim, alguns desafios demandaram reorientações estratégicas para que tais contratempos interferissem o mínimo possível no processo metodológico. Estes impeditivos foram desde problemas climáticos (chuva torrencial em um dos dias) a desentendimento em relação ao combinado com um professor acerca da cessão do horário, passando por questões referentes ao calendário escolar, à própria equipe de aplicadores e reações diversificadas dos alunos.

As aplicações dos questionários e do Jogo foram desenvolvidas propositalmente em horários pertencentes a professores(as) de áreas tipicamente desvinculadas de matérias que 
Ações Lúdico-Educativas para o enfrentamento da doença dengue em cinco escolas públicas da Grande Belo Horizonte: uma análise a partir da categoria sexo

envolvam ciências, como Artes, Português, Matemática, História, Geografia e Educação Física, para que não houvesse 'consulta' aos docentes por parte dos alunos durante a enquete. Tal tática se deveu porque, como já frisado, o escopo primordial dos questionários foi apanhar o conhecimento dos discentes sem outras interferências, intercalados somente pelo Jogo da Dengue. Houve também cuidado por parte da equipe com os períodos de provas internas, festividades cívicas ou religiosas, exposições e semanas de cunho científico/cultural.

Dois casos em específico marcaram o processo metodológico da pesquisa, sendo um deles decisivo na obtenção de dados amostrais pós-Jogo abaixo do rendimento prévio dos mesmos alunos de uma das melhores turmas do Ensino Médio do Instituto de Educação de Minas Gerais. O outro caso apenas contou com uma dificuldade de gestão dos protocolos pertinentes à aplicação, fator que pouco alterou o resultado, alertando a equipe para maior organização durante a elaboração e execução dos planejamentos para o futuro da pesquisa.

No caso da turma de Ensino Médio, ocorreu discordância entre o acordo verbal mediado pela supervisora e uma professora com a equipe Educação INCT Dengue/UFMG. No primeiro contato houve aceite e foi definido qual horário seria cedido para a aplicação. Porém, no dia da coleta de dados, durante os momentos iniciais da aplicação do questionário referente à etapa pós-Jogo, uma professora interrompeu o processo, adentrando na sala de aula abruptamente e questionando o uso do horário naquele dia. Alguns alunos manifestaram de antemão sua opção pela conclusão célere do questionário, além de conduzir boa parte da sala ao descrédito e ao desapontamento para com a atividade em andamento.

\section{Descrição e análise dos dados por eixos temáticos e por sexo}

O questionário conta com trinta e duas questões fechadas, sendo que em apenas uma questão estão presentes outras quatro subquestões, do tipo verdadeiro ou falso. Para a obtenção de uma perspectiva geral de todas as escolas por sexo, foi feita uma média de todas as questões do eixo, tomando-se o devido cuidado de separar o Ensino Fundamental do Ensino Médio. Somente um dos eixos temáticos não fez parte das questões fechadas - os aspectos psicológicos - que compuseram somente indagações atinentes às questões abertas do referido questionário.

Para melhor orientar tanto o processo de desenvolvimento do questionário e do Jogo quanto às análises dos resultados obtidos pela pesquisa, as definições dos eixos temáticos foram importantes indicadores amostrais que delimitaram assuntos, matérias e objetos 
teóricos que contribuíram para uma apreciação mais segura, significativa e legítima através do ponto de vista científico.

Assim, como foi dito, as perguntas foram divididas pelos seguintes eixos temáticos: 1ações domésticas e ações comunitárias; 2- ações político-sociais e ações governamentais; 3 aspectos biomédicos; 4- aspectos geográficos e climáticos e 5- aspectos psicológicos (analisados em outra oportunidade). Tal recurso possibilitou criar um panorama geral dos dados coletados e permitiu contrastar os dados quantitativos nas cinco escolas simultaneamente. Os mais altos índices em cada etapa de aplicação do questionário foram assinalados com cores tradicionalmente alusivas aos sexos: lilás para feminino e azul para masculino, estratégia que, embora assentada em estereótipos de gênero, facilita a imediata identificação do sexo que mais se destacou por eixo. Antes da apresentação e análise dos dados há que se fazer dois esclarecimentos para o entendimento dos números encontrados:

1- A comparação dos percentuais de erro e de acerto diz respeito aos números de meninos e de meninas enquanto grupos isolados entre si, desta forma, algumas vezes a soma dos percentuais ultrapassou $100 \%$, ou seja, o que se objetivou foi verificar qual grupo de sexo, percentualmente, acertou mais em dado eixo;

2- Tendo em vista que o número de alunas e de alunos poderia ser muito reduzido nesta ou naquela escola, esses percentuais dizem respeito a todas as meninas e a todos os meninos que participaram da pesquisa em cada nível de ensino, isto é, 52 alunos e 53 alunas do Ensino Fundamental e 19 alunos e 42 alunas do Ensino Médio nas cinco escolas.

\section{Eixo 1: ações domésticas e ações comunitárias}

Eixo temático com três questões apenas, apresentou assuntos correlatos às posturas comumente ligadas aos cuidados no lar, como práticas rotineiras para a prevenção e a orientação aos membros familiares sobre os meios de se evitar a dengue, além de conhecimentos e de condutas que envolvam prevenção e combate à dengue em suas comunidades imediatas.

\section{Ensino fundamental}

Os índices de acertos femininos foram superiores aos índices masculinos, o que destaca o tradicional papel do sexo feminino nos afazeres domésticos, no cuidado com 
Ações Lúdico-Educativas para o enfrentamento da doença dengue em cinco escolas públicas da Grande Belo Horizonte: uma análise a partir da categoria sexo

pessoas próximas, na troca de informações e saberes populares sobre doenças em suas comunidades etc., posturas essas que certamente possibilitaram às alunas melhor desenvoltura nas questões do eixo estudado, atitudes essas repassadas de geração em geração geralmente da mãe, tia ou avó para a filha e/ou neta e/ou sobrinha ou mesmo entre vizinhas. Nota-se que tanto os meninos quanto as meninas apresentaram aumento de índice de acertos depois do Jogo, na segunda aplicação do questionário. Abaixo, a média geral dos percentuais de acertos de todas as instituições pesquisadas por sexo antes e depois da aplicação do Jogo da Dengue:

Tabela 1 - Índice de acertos eixo temático 1 por sexo, Ensino Fundamental

\begin{tabular}{|c|c|c|}
\hline & Alunas & Alunos \\
\hline Pré-Jogo & $72,34 \%$ & $57,70 \%$ \\
\hline Pós-Jogo & $78,61 \%$ & $64,03 \%$ \\
\hline
\end{tabular}

\section{Ensino médio}

Os indicadores femininos permaneceram praticamente inalterados, embora tenham se ampliado um pouco nos resultados pós-Jogo em relação ao pré-Jogo, situação parecida ocorreu com os indicadores masculinos, não obstante os rapazes tenham tido relativa menor ampliação no seu percentual. Assim, os índices femininos permaneceram superiores aos masculinos. É interessante verificar que tanto no Ensino Fundamental quanto no Ensino Médio houve aumento do nível de acertos no pós-Jogo, o que pode indicar que o procedimento lúdico entre as duas aplicações pode ter contribuído de alguma maneira para aguçar a curiosidade sobre o tema ou até mesmo pode ter ajudado no processo de aprendizagem sobre a temática, quiçá suscitando o assunto em sala de aula ao longo da semana subsequente; tal inferência pode ser depreendida a partir da tabela abaixo:

Tabela 2 - Índice de acertos eixo temático 1 por sexo, Ensino Médio

\begin{tabular}{|c|c|c|}
\hline & Alunas & Alunos \\
\hline Pré-Jogo & $73,27 \%$ & $69,18 \%$ \\
\hline Pós-Jogo & $76,02 \%$ & $71,91 \%$ \\
\hline
\end{tabular}

\section{Eixo 2: Ações político-sociais e governamentais}

Eixo temático com quatro questões cujos objetivos foram examinar e conhecer o que os alunos e as alunas sabem sobre políticas sociais, iniciativas comunitárias, ações governamentais e suas concepções sobre o que e como estes assuntos são entendidos no 
cotidiano, como são divulgados pelas mídias e sob o ponto de vista pessoal e cultural de suas comunidades. Portanto, resumidamente é uma leitura do que as pessoas absorvem sobre as políticas públicas aplicadas à saúde coletiva relativa à dengue e suas consequências.

\section{Ensino fundamental}

Os índices femininos continuaram superiores aos masculinos nos questionários pré e pós-Jogo, mas agora apresentando sensível queda dos índices na pós-aplicação, redução que também foi verificada na média dos garotos de forma mais aguda, como visualizado a seguir:

Tabela 3 - Índice de acertos eixo temático 2 por sexo, Ensino Fundamental

\begin{tabular}{|c|c|c|}
\hline & Alunas & Alunos \\
\hline Pré-Jogo & $77,63 \%$ & $75,03 \%$ \\
\hline Pós-Jogo & $72,77 \%$ & $60,39 \%$ \\
\hline
\end{tabular}

\section{Ensino Médio}

Observou-se que a proeminência feminina apareceu de forma menos acentuada do que no Ensino Fundamental neste item, sobretudo na aplicação do questionário pós-Jogo, diminuindo um pouco a disparidade de sexo em ambos os momentos. Contudo, ainda assim mantiveram-se os maiores índices de acerto feminino.

Tabela 4 - Índice de acertos eixo temático 2 por sexo, Ensino Médio

\begin{tabular}{|c|c|c|}
\hline & Alunas & Alunos \\
\hline Pré-Jogo & $73,44 \%$ & $66,21 \%$ \\
\hline Pós-Jogo & $68,85 \%$ & $62,13 \%$ \\
\hline
\end{tabular}

\section{Eixo 3: aspectos biomédicos}

Eixo temático com o maior número de questões, vinte e uma ao todo, engloba dados mais científicos sobre a doença dengue, bem como aspectos outros variados como contágio, tratamento, gravidade, tipos da doença, sintomatologia e profilaxia, ou seja, aspectos mais 'escolares' e técnicos. 
Ações Lúdico-Educativas para o enfrentamento da doença dengue em cinco escolas públicas da Grande Belo Horizonte: uma análise a partir

\section{Ensino fundamental}

O índice da média feminina na primeira aplicação do questionário (pré-jogo) foi bem superior ao masculino, apresentando um quadro de crescimento demonstrativo de que o Jogo da Dengue, em certo sentido, conseguiu atingir parte significativa de seus objetivos, isto é, levar mais conhecimentos e discussões sobre o assunto. Tanto meninas quanto meninos tiveram índices de acerto ampliados na segunda aplicação do questionário, novamente ficando as meninas na frente dos meninos no percentual de acertos nas duas aplicações do questionário:

Tabela 5 - Índice de acertos eixo temático 3 por sexo, Ensino Fundamental

\begin{tabular}{|c|c|c|}
\hline & Alunas & Alunos \\
\hline Pré-Jogo & $63,84 \%$ & $53,36 \%$ \\
\hline Pós-Jogo & $72,77 \%$ & $62,86 \%$ \\
\hline
\end{tabular}

\section{Ensino médio}

Verificou-se um crescimento dos índices em ambos os sexos, com ampla vantagem feminina em todas as aplicações do questionário para este grupo de questões, ressaltando-se que as proporções em todas as aplicações do questionário por sexo continuam muito parecidas. Portanto, se assiste amplo crescimento em todas as duas aplicações do questionário nos dois níveis de ensino e nos dois sexos.

Tabela 6 - Índice de acertos eixo temático 3 por sexo, Ensino Médio

\begin{tabular}{|c|c|c|}
\hline & Alunas & Alunos \\
\hline Pré-Jogo & $72,77 \%$ & $60,39 \%$ \\
\hline Pós-Jogo & $83,04 \%$ & $70,93 \%$ \\
\hline
\end{tabular}

\section{Eixo 4: Aspectos geográficos e climáticos}

Eixo temático com reduzido número de questões, somente quatro, apresentou pequena vantagem masculina na primeira e também na segunda aplicação do questionário. Foi o único eixo em que os alunos superaram as alunas em um eixo do questionário, conseguindo repetir a vantagem percentual da pré-aplicação na pós-aplicação do Jogo. Não obstante a superioridade masculina neste item, as diferenças dos índices entre os sexos na pré e pós-aplicação são baixas. Aqui também se constatou o fenômeno do crescimento, tanto entre garotas quanto entre garotos, do nível de acerto na segunda e última aplicação do questionário se comparada 
à primeira, não obstante o percentual de acertos na aplicação pré-jogo, quando comparados com os índices dos eixos anteriores, foi sensivelmente menor, ou seja, pouco ultrapassou a marca dos $50 \%$.

\section{Ensino fundamental}

O equilíbrio dos dados, tanto na pré como na pós-aplicação do questionário revelam certo grau de equidade por sexo em relação aos conhecimentos geográficos e climáticos correlacionados à dengue. Apresentam, porém, pequena vantagem masculina.

Tabela 7 - Índice de acertos eixo temático 4 por sexo, Ensino Fundamental

\begin{tabular}{|c|c|c|}
\hline & Alunas & Alunos \\
\hline Pré-Jogo & $55,56 \%$ & $58,93 \%$ \\
\hline Pós-Jogo & $68,00 \%$ & $70,38 \%$ \\
\hline
\end{tabular}

\section{Ensino médio}

Os índices masculinos e femininos na pré e pós-aplicação do questionário entre $O$ Jogo da dengue permanecem com diferenças muito baixas entre si. Situação essa bastante parecida com a média do Ensino Fundamental. Porém, aqui no Ensino Médio verifica-se que as meninas ficaram mais próximas aos índices dos meninos e que ambos os grupos de sexo apresentaram maior percentual de acertos se comparados aos percentuais do Ensino Fundamental.

Tabela 8 - Índice de acertos eixo temático 4 por sexo, Ensino Médio

\begin{tabular}{|c|c|c|}
\hline & Alunas & Alunos \\
\hline Pré-Jogo & $68,00 \%$ & $70,42 \%$ \\
\hline Pós-Jogo & $76,27 \%$ & $77,43 \%$ \\
\hline
\end{tabular}

\section{Conclusões}

De modo geral os dados aqui encontrados se coadunam com o crescente número de mulheres como chefes de famílias, os indicadores estatísticos apresentando maior média de anos estudados no Ensino Básico e no Superior, além de comprometerem-se com afazeres domésticos e responsabilidades sociais de forma mais significativa que os homens recentemente, e revelam também o importante papel feminino, cada vez maior na sociedade 
Ações Lúdico-Educativas para o enfrentamento da doença dengue em cinco escolas públicas da Grande Belo Horizonte: uma análise a partir da categoria sexo

brasileira, confirmado pela Síntese de Indicadores Sociais publicada em 2013 pelo Instituto Brasileiro de Geografia e Estatística-IBGE.

Particularmente a partir dos dados coletados através das questões fechadas do questionário aplicado em dois momentos distintos, pré e pós Jogo da Dengue, nota-se que os índices femininos em praticamente todos os eixos temáticos sobre a dengue são superiores ao masculino. Mesmo no único item em que os meninos ficaram à frente - aspectos geográficos e climáticos - o percentual de acertos deles não se distanciou muito acima do percentual de acerto das meninas, porém, o contrário aconteceu: nos três primeiros itens o percentual de acertos das alunas, seja no Ensino Fundamental quanto no Médio, ficou cerca de 10 pontos à frente do índice de acertos dos meninos. Neste contexto, portanto, evidencia-se que há que se desenvolverem mudanças socioculturais e educacionais de gênero no intuito de que:

Incluir a participação do homem nas ações de saúde é, no mínimo, um desafio, por diferentes razões. Uma delas se refere ao fato de, em geral, o cuidar de si e a valorização do corpo no sentido da saúde, também no que se refere ao cuidar dos outros. Não serem questões colocadas na socialização dos homens (HARDY; JIMÉNEZ, 2000).

No que tange à escolaridade, pode-se perceber que ao ingressar no Ensino Médio há uma diminuição sensível do número de meninos em comparação com o número de meninas. Um apontamento preliminar pode, com isso, indicar uma realidade de que jovens do sexo masculino interrompem sua trajetória escolar em maior número do que as garotas ao findar o Ensino Fundamental, especialmente nas classes mais baixas.

Concernente à comparação entre os eixos temáticos, preponderou, em número de questões acertadas, o eixo dos aspectos biomédicos, tanto no Ensino Fundamental como no Médio, com vantagem geral significativa feminina. Aí foram investigados conhecimentos técnicos como formas de contágio, prevenção, sintomatologia, tratamento e profilaxia, demonstrando, segundo Schraiber et al. (2005), que os conhecimentos técnicos e científicos, alinhados ao universo historicamente masculino, aqui assumiram uma nova configuração, ou seja, as estudantes também começam a superá-los nesta área de conhecimento.

Nos demais eixos, ações domésticas e ações comunitárias, além de ações políticosociais e ações governamentais, as alunas também obtiveram os maiores índices em todas as etapas da pesquisa, demonstrando conhecimentos prévios razoavelmente superiores aos masculinos. Korin (2001) menciona as atribuições masculinas vinculadas ao sucesso e à força, distanciando-se de características relacionadas ao feminino, como a sensibilização, as posturas de dependência e cuidado, por exemplo. Assim, as representações simbólicas, 
responsáveis pelas diferenciações de sexo também são promotoras, em parte, de predisposições masculinas nas classes populares ao descuido com o corpo.

Não obstante, os programas governamentais para a saúde coletiva reforçam somente o importante papel da mulher na saúde e na conscientização coletiva através do conhecimento a respeito de sua comunidade, das escolas onde seus filhos estudam e como responsáveis pelos aspectos gerais de seus domicílios. Quando tais estudos e ações institucionais tentam trazer os homens como informantes e/ou alvos das ações institucionais, a situação acima descrita se altera, já que os homens são, histórica e culturalmente, mais 'distantes' das comunidades imediatas onde vivem e também das instituições de ensino onde estudam seus filhos, conforme relatado por Schraiber et al. (2005).

O eixo aspectos geográficos e climáticos apresentou rendimento masculino superior ao feminino, porém, houve queda dos indicadores em ambos os sexos na segunda aplicação do questionário, quiçá devido aos problemas burocráticos em uma das escolas, já relatados, posto que tais questões se encontram ao final da enquete. $\mathrm{O}$ rendimento masculino se reduziu ao nível bem próximo de equiparação ao feminino, logo, foi sutil a vantagem percentual de acertos masculina neste eixo.

Desta feita, a pesquisa não apenas ofereceu dados sobre aspectos variados e importantes sobre a dengue e saúde coletiva nos ambientes escolares, mas também favorece a elaboração e a avaliação para o aprimoramento de materiais didáticos de caráter lúdico. Permitiu também um espaço de reflexão e de discussão sobre relações sociais, políticas, econômicas e, claro, referentes às relações de gênero na escola e na comunidade. Alinhada às tendências de investigações científicas priorizadas nos últimos anos, aqui se destaca que:

Recentemente, o Ministério de Ciência e Tecnologia, por meio do CNPq e do Ministério da Saúde, pelo Departamento de Ciência e Tecnologia, tem lançado editais e financiamentos [...], que propiciam a ampliação e a legitimação da produção científica sobre gênero e saúde (AQUINO, 2006, p. 125).

Com efeito, o projeto Ações Educativas no Controle e Combate à Doença Dengue pretende prosseguir suas atividades investigativas relativas ao comportamento dos indivíduos em saúde coletiva pautado no ingresso dessas atividades nas escolas via PIBID. O Jogo da Dengue demanda por mais estudos, inclusive, baseados no tempo de aplicação do Jogo, fator muito discutido pela equipe Educação do INCT-Dengue durante a análise dos dados.

Os resultados demonstram, de forma geral, sucesso nas respostas obtidas pelas intervenções, porém, tornar-se-á necessário ampliar a pesquisa baseando-se na potencialidade 
Ações Lúdico-Educativas para o enfrentamento da doença dengue em cinco escolas públicas da Grande Belo Horizonte: uma análise a partir da categoria sexo

do Jogo em mais de uma aplicação. Portanto, como apontam Teixeira e Freitas (2013), investigar os conhecimentos prévios sobre dengue e propor novas metodologias e materiais no espaço escolar são os pilares do projeto que vislumbram a dengue também como um 'pretexto' para tratar de outras questões ligadas à saúde coletiva e às relações de gênero.

Finalmente, no que se refere à variável sexo em relação aos percentuais de acertos, verificou-se de modo inequívoco que os índices de conhecimentos femininos foram superiores aos masculinos em três dos quatro eixos avaliados, especialmente no Ensino Fundamental, onde apenas o eixo aspectos geográficos e climáticos foi superado pelos meninos. No Ensino Médio, os percentuais de acertos dos meninos sobem, porém ainda se mantêm inferiores aos femininos, à exceção, novamente, dos aspectos geográficos e climáticos.

Durante a coleta de dados verificou-se que os meninos têm um pouco mais de desenvoltura que as meninas para se expressarem, em contrapartida, as meninas eram mais focadas, concentradas e aplicadas, tanto que quase todos os grupos formados só por meninas, como já dito, mais comum no Ensino Fundamental, eram os que, com algumas exceções, terminaram o Jogo mais cedo. No caso do preenchimento do questionário, observou-se o oposto: as meninas terminavam mais tarde o preenchimento que os meninos, mas, em compensação, como foi apresentado nos gráficos, o índice de acerto delas foi maior que o deles. Logo, esta experiência corrobora que a equidade entre os sexos (assim como outros grupos de sujeitos) deve balizar as práticas escolares e o ensino como um todo, ou seja, meninas e meninos devem vivenciar as mesmas experiências, aulas práticas, visitas técnicas, terem acesso aos mesmos conteúdos e temas.

Quando era realizada a média por nível de ensino e por sexo antes e depois da aplicação do Jogo, percebeu-se que as questões de gênero foram similares nas cinco instituições, desde as que possuem mais alunos negros e pardos e estão situadas em região mais pobre da região metropolitana (na periferia da cidade de Sete Lagoas), à escola tida como 'modelo' (Pedro II), com predominância de alunos de classe média e, não raro, de classe média alta, e em sua maioria brancos e pardos. Tal constância mostra o atravessamento das questões de gênero nas questões de classe e raça no que concerne à produção social e cultural dos saberes e das futuras aptidões individuais/profissionais dos jovens.

Consequentemente, tendo o combate à doença dengue como mote, aqui se preconiza que é tarefa da escolarização conduzir a que meninos e meninas aprendam as mesmas coisas e que reflitam sobre seus papeis sociais ligados às questões de gênero em nossa sociedade, enfatizando-se também a exclusão dos preconceitos e a construção de novas formas de os 
sexos, desde a infância até a idade adulta, se relacionarem de modo mais igualitário, seja na escola, mas também na família, no âmbito da saúde e nas comunidades onde residem.

\section{REFERÊNCIAS}

ABRAMOVAY, M.; CASTRO, M. G. Relações raciais na escola: reprodução das desigualdades em nome da igualdade. Brasília: editora UNESCO, 2006.

AQUINO, E. M. L. Gênero e saúde: perfil e tendências da produção científica no Brasil. In: Caderno Saúde Pública. 1 ed. Rio de Janeiro, p. 125, 2006.

BRASIL. MINISTÉRIO DA EDUCAÇÃO. Parâmetros Curriculares Nacionais. Apresentação de Temas Transversais. Brasília: Secretaria de Educação Fundamental, 1998.

BRASIL. MINISTÉRIO DA SAÚDE. Programa Nacional de Controle da Dengue (PNCD). Brasília: Fundação Nacional de Saúde. Ministério da Educação, 2002.

BRASIL. IBGE. Sínteses de Indicadores Sociais: uma análise das condições de vida da população brasileira. Caderno Estudos \& Pesquisas: informação demográfica e socioeconômica, 32, Brasília, 2013. Disponível em: http:/biblioteca.ibge.gov.br/visualização/livros/liv66777.pdf. Acesso em: 19 nov. 2014.

FERNÀNDEZ, A. Aprendizagem também é uma questão de gênero. Nova Escola. 2012. Disponível em: http://acervo.novaescola.org.br/formacao/aprendizagem-tambem-questaogenero-432236.shtml. Acesso em: 04 maio 2016.

HARDY, E.; JIMÉNEZ, A. L. Masculinidad y género. Rio de Janeiro: Fiocruz, 2000.

KORIN, D. Novas perspectivas de gênero em saúde. Adolescência Latinoamericana, v. 2, n. 2, 2001.

MARIANO, Z. F.; SCOPEL, I.; SILVA, J. S. A Dengue no Brasil e as Políticas de Combate ao Aedes aegypti: da tentativa de erradicação às políticas de controle. Hygeia - Revista Brasileira de Geografia Médica e da Saúde. v. 3, n. 6, p. 163-175, jun. 2008.

RIBEIRO, P. R. C.; QUADRADO, R. P. Corpos, gênero e sexualidades: questões possíveis para o currículo escolar. 3 ed. revisada. Rio Grande: FURG, 2013.

SCHALL, V. T.; ASSIS, S. S.; PIMENTA, D. N. Educação em saúde como estratégia no controle integrado da dengue: reflexões e perspectivas. In: VALLE, Denise (org.). Dengue: teorias e práticas. Rio de Janeiro: Fiocruz, 2015.

SCHRAIBER, L. B.; GOMES, R.; Couto, M. T. Homens e saúde na pauta da saúde coletiva. Ciência \& Saúde Coletiva, v. 10, n. 1, p. 7-17, 2005.

SILVEIRA, A.; ATAÍDE, A. R. P.; FREIRE, M. L. F. Atividades lúdicas no ensino de ciências: uma adaptação metodológica através do teatro para comunicar a ciência a todos. Educar, n. 34, p. 251- 262, 2009. 
TEIXEIRA, A. B. M.; FREITAS, M. A. Informação de conhecimentos sobre Dengue entre discentes do ensino fundamental de escolas públicas da cidade de Sete Lagoas (Brasil). Outros Plurais - Mulheres e Homens na educação. ed. 1. Curitiba: CRV, 2013

VEIGA NETO, A. Didática e as experiências de sala de aula: uma visão pós-estruturalista. Educação \& Realidade, v. 21, n. 2, p. 161-175, jul/dez. 1996.

\section{Como referenciar este artigo}

FREITAS, M. de A.; AZEVEDO, T. G. de; TEIXEIRA, A. B. M. Ações lúdico-educativas para o enfrentamento da doença dengue em cinco escolas públicas da grande belo horizonte: uma análise a partir da categoria sexo. Revista Ibero-Americana de Estudos em Educação, Araraquara, v. 14, n. 4, p. 2222-2243, out./dez., 2019. E-ISSN: 1982-5587. DOI: https://doi.org/10.21723/riaee.v14i4.9938

Data de Submissão: 02/11/2017

Revisões Requeridas: 02/05/2018

Aceite em: 30/10/2018

Publicado em: 02/09/2019 